\title{
MONITORING KUALITAS UDARA MENGGUNAKAN ROBOT SAMPAH
}

\author{
Nyayu Latifah Husni ${ }^{1}$, Johansyah Al Rasyid ${ }^{2}$, M Rizki Hidayat ${ }^{3}$, \\ Yordan Hasan $^{4}$, Sabilal Rasyad ${ }^{5}$, Masayu Anisah ${ }^{6}$
}

\author{
Jurusan Teknik Elektro, Politeknik Negeri Sriwijaya Palembang \\ E-mail:, ${ }^{1}$ nyayu_latifah@polsri.ac.id , ${ }^{2}$ johansyah@polsri.ac.id, ${ }^{3}$ rizkihdyatt@gmail.com \\ ${ }^{4}$ yordan.hasan@gmail.com ,,$\underline{5}$ sabyad_ok@yahoo.co.id ,
}

\begin{abstract}
ABSTRAK Polusi udara merupakan permasalahan yang sampai sekarang masih belum bisa terselesaikan. Polusi udara dapat terjadi akibat adanya pembakaran yang tidak sempurna dari mesin kendaraan maupun proses industri yang menghasilkan gas-gas tidak baik bagi kesehatan. Senyawa gas yang terdapat pada udara yang terpolusi dapat berdampak buruk bagi kesehatan apabila kadarnya melampaui batas normal. Oleh karena ini, penelitian ini bertujuan untuk meningkatkan kesadaran tentang pentingnya kualitas udara yang sehat, sehingga masyarakat akan lebih peduli tentang kesehatan dan dapat meminimalisir risiko menghirup udara berbahaya. Pada penelitian ini ditawarkan sebuah robot sampah yang tidak hanya berfungsi sebagai kotak sampah, namun juga sebagai alat monitoring kualitas udara. Sistem monitoring pada penelitian ini dilengkapi dengan sensor $M Q 135$ yang berfungsi sebagai pendeteksi polusi udara dan sensor DHT22 yang berfungsi sebagai pendeteksi suhu dan kelembapan. Sistem monitoring yang dibangun pada penelitian ini juga dilengkapi dengan sistem komunikasi jarak jauh dengan memanfaatkan aplikasi Blynk. Hasil monitoring kualitas udara pada penelitian ini akan menampilkan 3 kondisi kualiats udara di sekitar, yaitu: baik, sedang dan buruk. Dengan adanya informasi yang diberikan oleh robot sampah pada penelitian ini, masyarakat dapat mengetahui kondisi kualitas udara di tempat tersebut. Hal ini tentu saja sangat bermanfaat bagi manusia. Dengan adanya informasi tersebut, manusia dapat mengetahui apakah tempat tersebut aman ataukah berbahaya bagi kesehatan mereka.
\end{abstract}

Kata kunci : Polusi Udara, Kualitas Udara, Monitoring, MQ135, DHT22

\begin{abstract}
Air pollution is a problem that still cannot been solved. Air pollution can occur due to the imperfect combustion from vehicle engines and or industrial processes that produce gases that are not good for health. If the levels of gas compounds found in polluted air exceed normal limits, it can give bad impact to the health. Therefore, this study aims to raise an awareness for the human about the importance of healthy air quality. By raising their awareness, they will be more concerned about health that canlead to the minimalization of the risk of inhalling dangerous air. This research offers a garbage robot that not only has functions as a garbage box, but also as an air quality monitoring device. The monitoring system in this study is equipped with MQ135 sensor that functions as a detector of air pollution and a DHT22 sensor that functions as a detector of temperature and humidity. The monitoring system built in this study is also equipped with a long-distance communication system by utilizing the Blynk application. The results of air quality monitoring in this study will show three conditions of air quality, namely: good, moderate and bad. By having the information provided by the garbage robot in this study, the public can find out the condition of the air quality at that site. This system, of course, is very beneficial for humans. With the information of air quality, people can find out whether the place is safe or dangerous to their health.
\end{abstract}

Keywords: Air Pollution, Air Quality, Monitoring, MQ135, DHT22

\section{PENDAHULUAN}

Oksigen merupakan senyawa gas di udara yang sangat penting untuk kehidupan. Oksigen di dalam maupun di luar ruangan dapat terkontaminasi dengan zat-zat yang berbahaya bagi kesehatan. Dalam batasan tertentu, kadar zat - zat tersebut masih dapat dinetralisir namun jika melampaui batas normal maka dapat mengganggu kesehatan. World Health Organization (WHO) menyatakan bahwa terdapat zat berbahaya yang berasal dari bangunan, material konstruksi, peralatan, proses pembakaran atau pemanasan dapat memicu masalah kesehatan. 
Pada tahun 2014, World Health Organization (WHO) [1] menyatakan bahwa 7 juta angka kematian terjadi setiap tahun disebabkan oleh kadar tingginya polusi udara. The World Health Organization [2], diketahui bahwa kebutuhan udara bersih untuk manusia adalah 10-20 $\mathrm{m}^{3}$ per hari.

Polusi udara saat ini semakin menampakkan kondisi yang memprihatinkan. Polusi udara terjadi akibat pembakaran yang tidak sempurna dari mesin kendaraan maupun proses industri yang menghasilkan gas-gas yang mengandung zat yang tidak baik bagi kesehatan akibat dari pembakaran yang tidak sempurna dan dapat berdampak negatif terhadap kesehatan manusia. Dampak polusi udara terhadap kesehatan dapat terjadi baik secara langsung maupun tidak langsung. Gangguan kesehatan yang terjadi secara langsung dapat berupa iritasi mata, iritasi hidung, sakit tenggorokan, sakit kepala, mual, asma, dan penyakit-penyakit lainnya [3]-[5]. Sedangkan gangguan kesehatan secara tidak langsung dampaknya dapat terjadi beberapa tahun kemudian seperti penyakit paru-paru, jantung dan kanker yang sulit diobati yang berakibat fatal (USEPA, 2007).

Berdasarkan latar belakang tersebut, penelitian ini menawarkan sebuah sistem monitoring kualitas udara dengan memanfaatkan LCD, buzzer dan LED yang akan menampilkan hasil monitoring dan aplikasi blynk yang bertindak sebagai sistem notifikasi jarak jauh. Kadar udara yang dideteksi akan dibagi menjadi 3 kategori berdasarkan Indeks Standar Pencemaran Udara (ISPU), yaitu indikator LED berwarnah hijau untuk kualitas udara dalam keadaan baik, kuning untuk kualitas udara sedang dan apabila kualitas udara dalam keadaan buruk maka LED merah dan buzzer akan menyala sebagai indikator peringatan bahwa udara di sekitar telah tercemar.

Beberapa peneliti sebelumnya sudah banyak yang membahas masalah monitoring kualitas udara, diantaranya pada penelitian [6]-[13], baik monitoring kualitas udara secara statik maupun mobile. Monitoring secara mobile akan memberikan keuntungan, dimana jangkauan area yang dimonitoring dapat diperluas. Pada penelitian ini, komponen monitoring kualitas udara diletakkan pada robot sampah. Robot sampah ini tidak hanya berfungsi sebagai kotak sampah, namun juga berfungsi sebagai alat monitoring kualitas udara. Dengan adanya penelitian ini, diharapkan masyarakat akan lebih peduli terhadap lingkungan dan kesehatan guna mewujudkan 2 dari 6 indikator konsep Smart City, yaitu: Smart Environment, dengan meningkatkan sumber daya alam ramah lingkungan dan Smart Living, dengan mewujudkan kota sehat layak huni.

\section{PERANCANGAN SISTEM}

Tujuan dari perancangan yaitu untuk mendapatkan hasil akhir yang baik seperti yang diharapkan dan dengan adanya tahap perancangan, akan memberikan kemudahan dalam mencari dan memperbaikki kerusakan peralatan atau rangkaian. Selain itu dengan adanya perancangan yang sistematis dan saling berkaitan, akan diperoleh alat dengan spesifikasi yang baik.

\section{Perancangan Perangkat Keras}

Blok diagram perangkat robot sampah secara keseluruhan dapat dilihat pada Gambar 1 di bawah ini. Seperti yang digambarkan pada Gambar 1, robot sampah menerima masukkan dari sensor $M Q 135$, sensor DHT22, sensor proximity, sensor ultrasonik dan sensor warna. Sedangkan Output dari robot sampah berupa $L C D, L E D$, motor PG45, Buzzer, aktuator motor linear. Seluruh komponen diatur oleh Arduino Mega 2560 + wifi yang dikendalikan menggunakan aplikasi blynk. 
Penelitian yang disajikan pada paper ini hanya membahas aplikasi monitoring kualitas udaranya saja, yang ditunjukkan oleh box dengan garis putus-putus pada Gambar 1.

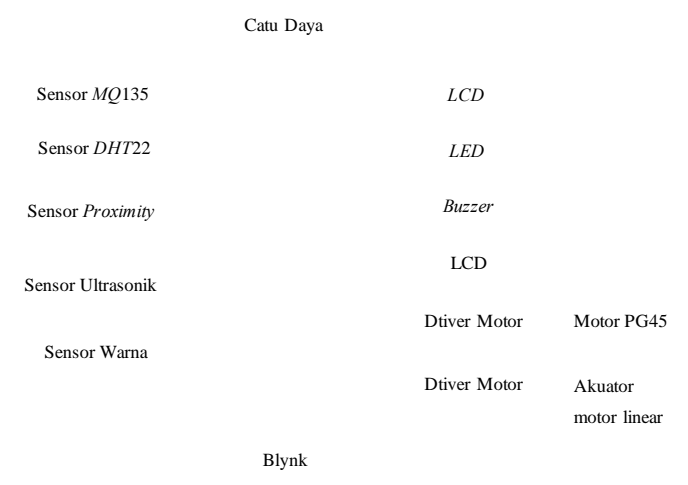

Gambar 1. Blok diagram robot sampah

Sensor $M Q 135$ dan sensor DHT22 yang terdapat pada bagian input berfungsi sebagai pemonitor kualitas udara yang ada di sekitar robot sampah. Sensor $M Q 135$ akan mendeteksi kadar udara (berupa perubahan nilai resistensi analog pada pin keluarannya), sedangkan sensor DHT22 akan mendeteksi suhu dan kelembapan. Data yang telah dideteksi, kemudian dikirim ke mikrokontroler. Mikrokontroler akan menghasilkan output berupa: 1) kadar udara dalam satuan Part Per Million (PPM), 2) suhu dalam satuan ${ }^{\circ} \mathrm{C}$, dan 3) kelembapan di udara dalam satuan \%. Output ini akan ditampilkan melalui 4 buah perangkat, yaitu: 1) mobile phone (melalui aplikasi Blynk), 2) $L C D, 3)$ LED dan juga 4) buzzer. Apabila jumlah ppm di udara melebihi ambang batas berdasarkan Indeks Standar Pencemaran Udara (ISPU) maka buzzer akan berbunyi sebagai tanda peringatan bahwa udara disekitar sudah tercemar.

Input berupa sensor MQ135 dan sensor DHT22 yang ditujukkan pada Gambar 1 diletakan di bagian badan robot. Seperti dijelaskan diatas, Sensor $M Q 135$ dan sensor DHT22 akan memonitoring kualitas udara disekitar robot sampah. Sensor MQ135 akan mendeteksi kadar udara dengan cara membaca nilai Analog Data Converter (ADC) atau dari perubahan resistansi sensor, kemudian data akan diolah menjadi Part Per Million (PPM), yang merupakan satuan zat polutan. Sensor DHT22 akan mendetelsi suhu dan kelembapan. Data kedua sensor ini kemudian dikirim ke arduino mega (mikrokontroler).

Output dari sistem monitoring kualitas udara pada penelitian ini (Gambar 1), berupa $L C D$ dan $L E D$ yang diletakan di bagian depan robot sampah, serta buzzer yang diletakkan di dalam robot sampah. Setelah data kadar udara, suhu dan kelembapan yang berasal dari telah diolah oleh arduino mega, data tersebut kemudian dikirim ke bagian output. Data kadar udara, suhu dan kelembapan serta kualitas udara apakah baik, sedang dan buruk akan ditampil pada mobile phone, $L C D$ dan $L E D$, dimana $L E D$ hijau mengindikasikan kualitas udara baik, $L E D$ kuning mengindikasikan kualitas udara sedang dan $L E D$ merah mengindikasikan kualitas udara buruk. Jika kualitas udara buruk, maka buzzer akan berbunyi sebagai tanda peringatan bahwa udara di sekitar robot sampah melebihi Indeks Standar Pencemaran Udara (ISPU).

\section{Perancangan Perangkat Lunak}

Hal pertama yang dilakukan dalam tahapan perancangan perangkat lunak (software) adalah membuat alur program (flowchart) dari program yang akan dibuat. Dengan adanya flowchart, maka arah dari jalannya program dapat dipahami. Flowchart perangkat lunak pada penelitian ini, dapat dilihat pada Gambar 2 berikut: 


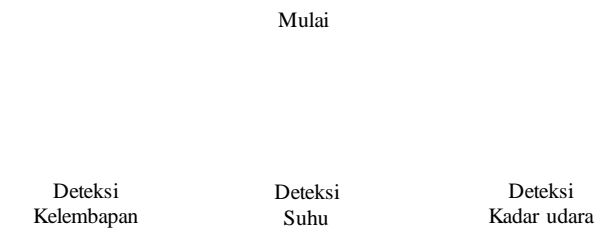

Menentukan kualitas udara

Gambar 2. Flowchart sistem monitoring kualitas udara

\section{Perancangan Elektronik}

Sistem monitoring kualitas udara pada penelitian ini menggunakan berbagai komponen, diantaranya $M Q 135, D H T 22, L E D, L C D$ dan buzzer. Hubungan wiring untuk masing-masing komponen dapat dilihat pada Gambar 3 dibawah ini.



Gambar 3. Rangkaian komponen

\section{Perancangan Mekanik}

Mekanik robot dapat dilihat pada Gambar 4. Robot terdiri dari beberapa bagian, diantaranya: kepala robot dan body robot. Kepala robot dan body robot ini dapat digerakkan ke depan dan ke belakang, sehingga memudahkan untuk membuang sampah serta membersihkan robot sampah itu sendiri. 


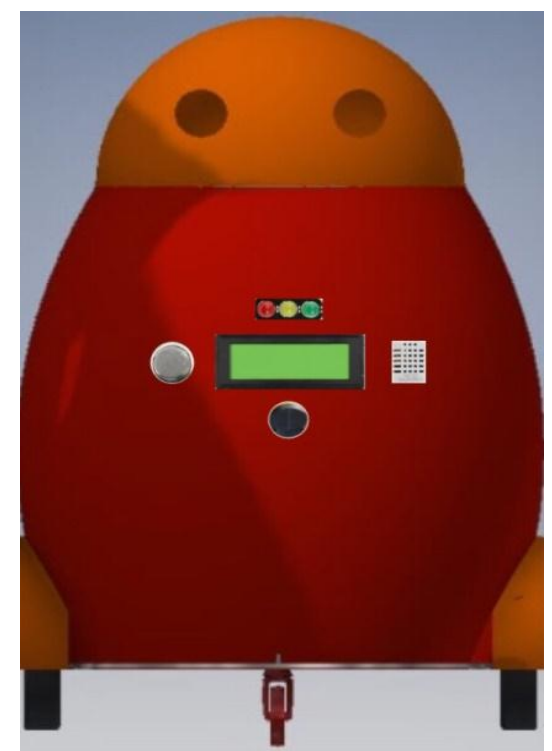

Gambar 4. Mekanik robot

\section{Monitoring Menggunakan Mobile Phone}

Pada penelitian ini, monitoring menggunakan mobile phone dirancang dengan menggunakan aplikasi Blynk. Tampilan monitoring menggunakan mobile phone dapat dilihat pada Gambar 5.

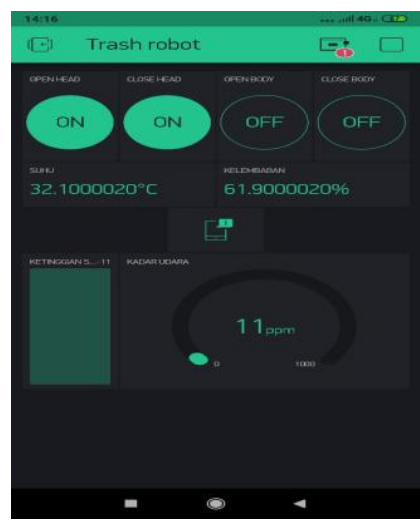

Gambar 5. Monitoring menggunakan mobile phone

\section{HASIL DAN PEMBAHASAN}

Pengujian alat monitoring kualitas udara ini dibagi menjadi empat bagian, yaitu: 1) pengujian sensitivitas output terhadap perubahan konsentrasi gas (input). Perubahan konsentrasi gas didapat dengan cara memberikan gas butana tepat di atas sensor MQ135 selama selang waktu yang berbeda-beda. Gas butana pada penelitian ini dihasilkan dari korek api gas; 2) pengujian alat di ruangan $A C$ dan tanpa $A C$ pada waktu pagi hari; 3) pengujian alat di ruangan AC dan tanpa AC pada waktu siang hari; dan 4) pengujian alat di ruangan AC dan tanpa AC pada waktu malam hari

\section{Pengujian sensitivitas output terhadap perubahan konsentrasi gas}

Pengujian pertama yang dilakukan dalam penelitian ini adalah dengan cara menguji coba sensitivitas keluaran (output) sistem terhadap perubahan konsentrasi gas (input). Data hasil pengujian ditunjukkan pada Tabel 1. Dari Tabel 1 tersebut dapat dilihat bahwa komponen 
output dapat bekerja dengan baik. Semua komponen dapat merespon perubahan input (berupa perubahan konsentrasi gas) dengan baik.

Pada pengujian ini, ketika gas pada korek api didekatkan pada sensor $M Q 135$ selama 1 dan 2 detik, maka tegangan keluaran (Vout) yang dihasilkan sensor $M Q 135=0.57 \mathrm{~V}$ dan 0.78 $\mathrm{V}$ atau setara dengan 112 dan $156 \mathrm{ppm}$. Berdasarkan Indeks Standar Pencemaran Udara (ISPU), kedua nilai ini termasuk kedalam kategori sedang, sehingga $L E D$ kuning menyala. Ketika gas yang dihasilkan oleh korek api didekatkan pada sensor $M Q 135$ selama 3, 4, dan 5 detik, maka tegangan keluaran (Vout) yang dihasilkan sensor $M Q 135=2.2 \mathrm{~V}, 2.86 \mathrm{~V}$, dan 3.15 $\mathrm{V}$ atau setara dengan $432 \mathrm{ppm}, 568 \mathrm{ppm}$, dan . $623 \mathrm{ppm}$. Berdasarkan Indeks Standar Pencemaran Udara (ISPU), ketiga nilai ini termasuk dalam kategori buruk, sehingga LED merah menyala.

Dari data yang didapat, diketahui bahwa tegangan yang didapat dari hasil pengukuran dipengaruhi oleh jumlah kadar gas yang dideteksinya. Semakin tinggi kadar gas terdeteksi, maka semakin tinggi pula tegangan yang diperoleh sensor. Pembacaan sensor juga dipengaruhi oleh waktu kerja sensor. Sensor akan membutuhkan beberapa waktu untuk menyetabilkan tegangan dan kondisi sensor.

Tabel 1. Pengujian sensitivitas output

\begin{tabular}{|c|c|c|c|c|c|}
\hline waktu (s) & $\begin{array}{c}\text { Kadar Udara } \\
(\mathrm{ppm})\end{array}$ & Vout $(\mathrm{V})$ & LED & Buzzer & Kategori \\
\hline 1 & 112 & 0,57 & Kuning & OFF & Sedang \\
\hline 2 & 156 & 0,78 & Kuning & OFF & Sedang \\
\hline 3 & 432 & 2,2 & Merah & ON & Buruk \\
\hline 4 & 568 & 2,86 & Merah & ON & Buruk \\
\hline 5 & 623 & 3,15 & Merah & ON & Buruk \\
\hline
\end{tabular}

\section{Pengujian alat monitoring di ruangan AC dan tanpa AC pada waktu pagi hari}

Pengujian kedua dilakukan dengan cara menguji kinerja alat monitoring ketika pagi hari. Pengujian dilakukan dengan menggunakan 2 kondisi, yaitu kondisi pada ruangan ac dan ruangan tanpa ac. Hasil pengujian dapat dilihat pada Tabel 2.

\section{Pengujian alat monitoring di ruangan AC dan tanpa AC pada waktu siang hari}

Pengujian ketiga dilakukan dengan cara menguji kinerja alat monitoring ketika siang hari. Pengujian juga dilakukan dengan menggunakan 2 kondisi, yaitu kondisi pada ruangan ac dan ruangan tanpa ac. Hasil pengujian dapat dilihat pada Tabel 3.

\section{Pengujian alat monitoring di ruangan $\mathrm{AC}$ dan tanpa $\mathrm{AC}$ pada waktu malam hari}

Pengujian keempat dilakukan dengan cara menguji kinerja alat monitoring ketika malam hari. Pengujian dilakukan juga dengan menggunakan 2 kondisi (seperti pada pengujian kedua dan ketiga), yaitu kondisi pada ruangan ac dan ruangan tanpa ac. Hasil pengujian dapat dilihat pada Tabel 4.

Tabel 2. Data pengujian alat diruangan AC dan tanpa AC pada waktu pagi hari

\begin{tabular}{|c|c|c|c|c|c|c|c|c|c|c|}
\hline \multirow{2}{*}{$\begin{array}{c}\text { Jam } \\
(\text { WIB })\end{array}$} & \multicolumn{2}{|c|}{ Kadar Udara $(\mathrm{ppm})$} & \multicolumn{2}{c|}{ Suhu $\left({ }^{\circ} \mathrm{C}\right)$} & \multicolumn{2}{c|}{ Kelembapan $(\%)$} & \multicolumn{2}{c|}{ LED } & \multicolumn{2}{c|}{ Buzzer } \\
\cline { 2 - 11 } & AC & Tanpa AC & AC & Tanpa AC & AC & Tanpa AC & AC & Tanpa AC & AC & Tanpa AC \\
\hline 06.00 & 29 & 27 & 26.07 & 29,67 & 66,87 & 60,23 & Hijau & Hijau & OFF & OFF \\
\hline 07.00 & 29 & 27 & 26.01 & 29,98 & 68,74 & 59,56 & Hijau & Hijau & OFF & OFF \\
\hline 08.00 & 29 & 28 & 25.87 & 30,12 & 62,03 & 62,07 & Hijau & Hijau & OFF & OFF \\
\hline 09.00 & 31 & 29 & 24.54 & 30,36 & 72,34 & 63,06 & Hijau & Hijau & OFF & OFF \\
\hline 10.00 & 32 & 29 & 24.07 & 30,24 & 72,73 & 63,02 & Hijau & Hijau & OFF & OFF \\
\hline
\end{tabular}


Tabel 3. Data pengujian alat diruangan AC dan tanpa AC pada waktu siang hari

\begin{tabular}{|c|c|c|c|c|c|c|c|c|c|c|}
\hline \multirow{2}{*}{$\begin{array}{c}\text { Jam } \\
\text { (WIB) }\end{array}$} & \multicolumn{2}{|c|}{ Kadar Udara $(\mathrm{ppm})$} & \multicolumn{2}{|c|}{ Suhu $\left({ }^{\circ} \mathrm{C}\right)$} & \multicolumn{2}{c|}{ Kelemban $(\%)$} & \multicolumn{2}{c|}{ LED } & \multicolumn{2}{c|}{ Buzzer } \\
\hline 12.00 & $4 \mathrm{AC}$ & Tanpa AC & AC & Tanpa AC & AC & Tanpa AC & AC & Tanpa AC & AC & Tanpa AC \\
\hline 13.00 & 42 & 35 & 28,12 & 32,01 & 62,78 & 54,37 & Hijau & Hijau & OFF & OFF \\
\hline 14.00 & 41 & 35 & 28,78 & 32,28 & 63,67 & 54,09 & Hijau & Hijau & OFF & OFF \\
\hline 15.00 & 42 & 32 & 27,03 & 33,02 & 63,08 & 53,65 & Hijau & Hijau & OFF & OFF \\
\hline 16.00 & 43 & 32 & 27,01 & 33,91 & 62,37 & 53,97 & Hijau & Hijau & OFF & OFF \\
\hline
\end{tabular}

Tabel 4. Data pengujian alat diruangan $\mathrm{AC}$ dan tanpa $\mathrm{AC}$ pada waktu malam hari

\begin{tabular}{|c|c|c|c|c|c|c|c|c|c|c|}
\hline \multirow{2}{*}{$\begin{array}{c}\text { Jam } \\
(\text { WIB })\end{array}$} & \multicolumn{2}{|c|}{ Kadar Udara $(\mathrm{ppm})$} & \multicolumn{2}{|c|}{ Suhu $\left({ }^{\circ} \mathrm{C}\right)$} & \multicolumn{2}{c|}{ Kelembapan $(\%)$} & \multicolumn{2}{|c|}{ LED } & \multicolumn{2}{c|}{ Buzzer } \\
\hline 18.00 & AC & Tanpa AC & AC & Tanpa AC & AC & Tanpa AC & AC & Tanpa AC & AC & Tanpa AC \\
\hline 19.00 & 54 & 59 & 26,87 & 29,83 & 72,46 & 61,34 & Hijau & Hijau & OFF & OFF \\
\hline 20.00 & 57 & 54 & 26,06 & 29,42 & 72,09 & 61,46 & Hijau & Hijau & OFF & OFF \\
\hline 21.00 & 54 & 52 & 26,59 & 29,54 & 73,48 & 63,21 & Hijau & Hijau & OFF & OFF \\
\hline 22.00 & 51 & 52 & 26,96 & 27,86 & 72,24 & 65,72 & Hijau & Hijau & OFF & OFF \\
\hline
\end{tabular}

Semua data yang ditampikan pada Tabel 1 sampai dengan Tabel 4, diambil dari data pengukuran dan juga data tampilan pada LED dan juga mobile phone (seperti yang ditunjukkan pada Gambar 5). Berdasarkan Tabel 2, Tabel 3 dan Tabel 4, kualitas udara pada ruangan yang mengunakan AC dan tanpa AC pada waktu pagi, siang dan malam, ditemukan perbedaan kualitas udara yang terjadi di antara ruang yang mengunakan AC dan tanpa AC. Pada pagi hari, rata-rata kadar udara pada ruangan yang menggunakan $\mathrm{AC}$, adalah $30 \mathrm{ppm}$, sedangkan rata-rata suhu udara dan kelembapan adalah $25,31^{\circ} \mathrm{C}$ dan $68,54 \%$.Pada ruang yang tanpa AC, rata-rata kadar udara yang diperoleh sebesar 28 ppm, sedangkan rata-rata suhu udara dan kelembapan adalah $30,07^{\circ} \mathrm{C}$ dan $61,59 \%$.

Pada siang hari, ruangan yang menggunakan AC memiliki rata-rata kadar udara sebesar $41,8 \mathrm{ppm}$, sedangkan rata-rata suhu udara dan kelembapan sebesar $27,69^{\circ} \mathrm{C}$ dan $62,86 \%$. Pada ruang yang tanpa $\mathrm{AC}$, rata-rata kadar udara yang diperoleh sebesar $34 \mathrm{ppm}$, sedangkan suhu udara dan kelembapan sebesar $32^{\circ} \mathrm{C}$ dan $53,80 \%$.

Pada malam, ruangan yang menggunakan AC memiliki rata-rata kadar udara sebesar 56,4.ppm, sedangkan rata-rata suhu udara dan kelembapan sebesar $26,56^{\circ} \mathrm{C}$ dan $72,69 \%$. Pada ruang yang tanpa $\mathrm{AC}$, rata-rata kadar udara yang diperoleh sebesar 54,2 ppm, sedangkan suhu udara dan kelembapan sebesar $29,04^{\circ} \mathrm{C}$ dan $63,58 \%$.

Ruang yang menggunakan AC mempunyai kadar udara dengan ppm yang lebih besar dibandingkan ruang yang tidak mengunakan AC, sehingga mengakibatkan adanya perbedaan kualitas udara. Hal ini dikarenakan pada ruang yang menggunakan AC udara yang bersirkulasi hanyalah udara yang berada di ruangan. Udara hanya berputar-putar di dalam ruang tersebut. Sedangkan, pada ruang yang tanpa menggunakan AC, udara dapat bersirkulasi secara bergantian di dalam ruangan. Suhu dan kelembapan berpengaruh terhadap kualitas udara dalam suatu ruangan yaitu ketika kadar udara tinggi maka suhu dan kelembapan udara akan naik. Pada ruangan menggunakan AC dan tanpa AC perbedaan kualitas udara hanya sedikit dan kadar udara pada ruangan AC dan tanpa AC berdasarkan Indeks Standar Pencemaran Udara (ISPU) masih dalam kategori baik 


\section{KESIMPULAN}

Berdasarkan hasil analisa dan pengukuran dapat diambil kesimpulan bahwa sistem monitoring kualitas udara yang telah dibuat dan diuji pada penelitian ini mampu menampilkan informasi kualitas udara, suhu udara dan kelembapan udara menggunakan sensor $M Q 135$ dan DHT22.

\section{DAFTAR PUSTAKA}

[1] WHO, "A wealth of information on global public health," 2014.

[2] WHO Regional Office for Europe, "WHO guidelines for indoor air quality," Nutr. J., vol. 9, p. 454, 2010.

[3] J. Sun, J. Mei, H. Li, and J. Shi, "Reschedule Your Travel Plans : Human Health and Air Pollution," J. Travel Res. SAGE, no. 11, 2018.

[4] S. Tian, T. Liang, and K. Li, "Fine road dust contamination in a mining area presents a likely air pollution hotspot and threat to human health," Environ. Int., vol. 128, no. April, pp. 201-209, 2019.

[5] A. De Marco et al., "Impacts of air pollution on human and ecosystem health , and implications for the National Emission Ceilings Directive : Insights from Italy," Environ. Int., vol. 125, no. November 2018, pp. 320-333, 2019.

[6] T. Cieplak, T. Rymarczyk, and R. Tomaszewski, "A concept of the air quality monitoring system in the city of Lublin with machine learning methods to detect data outliers," vol. 03009, 2019.

[7] N. Ullah et al., "Optimal Real-time Static and Dynamic Air Quality Monitoring System," vol. 13, no. January, pp. 91-102, 2020.

[8] A. S. Mih, "Evaluating air quality by combining stationary, smart mobile pollution monitoring and data-driven modelling," 2019.

[9] V. Rao, "SmartAIR : Smart energy efficient framework for large network of air quality monitoring systems," 2019.

[10] Y. Wang, "Mobile Solutions to Air Quality Monitoring," pp. 1-11.

[11] A. S. Handayani, N. L. Husni, R. Permatasari, and C. R. Sitompul, "Implementation of Multi Sensor Network as Air Monitoring Using IoT Applications," in 34th International Technical Conference on Circuits/Systems, Computers and Communications, ITC-CSCC 2019, 2019.

[12] N. L. Husni, A. Silvia, S. Nurmaini, and others, "New Challenges in Air Quality Sensing using Robotic Sensor Network," Int. Conf. Innov. Eng. Technol., pp. 236-239, 2013.

[13] M. Annisah, N. L. Husni, T. Dewi, and R. M. A. Rachmawati, "Peat Land Fire Monitoring System Using Fuzzy Logic Algorithm,” vol. 8, no. 3, pp. 181-188, 2019. 